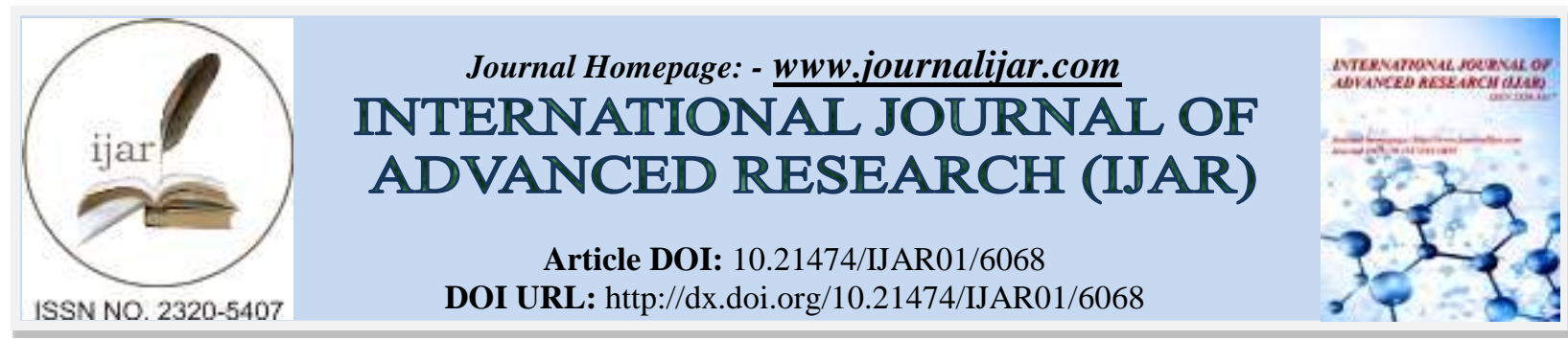

RESEARCH ARTICLE

\title{
DYNAMIC MODELLING OF ESCHERICHIA COLI GROWTH IN WATER DISTRIBUTION SYSTEM (A CASE STUDY: WATER SUPPLY ZONE 3 IN SURABAYA INDONESIA).
}

Eka dian srikandi and nieke karnaningroem.

Department of Environmental Engineering, Institut Teknologi Sepuluh Nopember, Surabaya 60111 Indonesia.

\section{Manuscript Info}

Manuscript History

Received: 15 October 2017

Final Accepted: 17 November 2017

Published: December 2017

Key words:-

Bacteria, pipeline leakage, simulation, STELLA 9.1.3.

\begin{abstract}
Escherichia coli is the biological standard in determining the quality of water in the distribution network. Chlorine residual, distribution distances, and $\mathrm{pH}$ are variables which can affect the quality of water distribution system. However, the reality showed that the pipeline leakage was one of the unpredictable existence variables which can also has a significant effect on the Escherichia coli in the distribution network. Therefore, by using STELLA 9.1.3, the dynamic model simulated the PDAM distribution network to modelling Escherichia coli in the nearest consumer from treatment plant based on two main scenarios, extreme scenario and optimum scenario. The simulation results showed that the highest pipeline leakage persentation might cause Escherichia coli growth eventhough it was at the nearest consumer. Thus, in order to reduce public health risk, it is necessary to repair pipes and to inject disinfectant when pipeline leaks have been detected.
\end{abstract}

Copy Right, IJAR, 2017,. All rights reserved.

\section{Introduction:-}

One of the government's mandates in Presidential Regulation No. 2 of 2015 on National Medium-Term Development Plan (RPJMN) for 2015-2019 periods is $100 \%$ access to decent drinking water services for all levels of the Indonesian community (universal access). The main target of universal access is $60 \%$ safe access to drinking water through piped networks and $40 \%$ safe access to drinking water through non-piped protected networks and achieving $100 \%$ healthy PDAM (Indonesian regional water supply company) in Indonesia.

Minister of Health Regulation No. 492/Menkes/SK/IV/2010 was issued by the government as the quality standard for drinking in Indonesia. In the regulation, drinking water can be categorized as safe for health when it meets the physical, microbiological, chemical, and radioactive requirements ${ }^{[4]}$. Therefore, a research is necessary in order to provide a simple and systematic description of the factors affecting water quality in PDAM distribution network through a dynamic model.

The Escherichia coli is the standard in determining the quality of water in the distribution network. The presence of chlorine residual itself is necessary to maintain the quality of piped water. Giving chlorine can reduce the microbial growth and the risk of contamination in the distribution network (Sugiarti et al., 2014). A study conducted by Retnowati (2015) shows a strong correlation between chlorine and Escherichia coli. This study concludes thatchlorine reduction could indicate the presence of Escherichia coli bacteria in water at the PDAM distributionnetwork. Meanwhile, a study conducted by Andhika (2013) indicates that there will be a reduction of Escherichia coli bacteria 
in chlorine-injected water at the distribution network. According to Afrianita et al. (2016), there are other variables which affect the reduction of chlorine residual in the distribution network, i.e. the distribution distance. The further the distribution distance, the less chlorine residual level will be. The chlorine residual also affects the $\mathrm{pH}$ of water although it is not significant. The water on the network tends to be acid when the chlorine injection is more.

Based on previous studies mentioned above, the variables such as chlorine residual, Escherichia coli, distribution distances, and $\mathrm{pH}$ will affect the quality of water received by consumers. However, the reality shows that these four variables are not the only variables which can affect the quality of water distribution. The pipeline leakage is one of the unpredictable existence variables which can also have a significant effect on the Escherichia coli in the distribution network. Since the percentage of pipeline leakage can only be assumed, the water quality of PDAM cannot be predicted which may result in the occurrence of leakage at sudden time. Therefore, by using STELLA 9.1.3, the dynamic model of the PDAM distribution network is simulated with variables of chlorine residual, Escherichia coli, distribution distance, $\mathrm{pH}$, and pipeline leakage so that water quality data can be obtained in the form of Escherichia coli with the percentage of a certain pipeline leakage experienced consumers.

\section{Methods:-}

Several steps were required in making the dynamic model structure of PDAM network distribution by using STELLA 9.1.3These steps included designing the conceptual model, making stock-flow diagram, model verification and validation, and also model simulation. The model simulations were divided into two scenarios, the extreme scenario and the optimum scenario, withdifferent pipeline leakage percentages. Extreme scenario has $70 \%$ pipeline leakage, meanwhile the optimum scenario had 10\% pipeline leakage (PDAM Surabaya, 2017).

\section{Designing the Conceptual Model:-}

In this step, the related variables were identified. These variables affected each component system which then were formed as a causal loop diagram from the PDAM distribution network.

\section{A. Variable Identification}

The variables used in this research are pipe leakage, water flow production, water flow distribution network distribution, distribution distance, water velocity, major head loss, pipe cross-sectional area, and pipe diameter. Meanwhile, the parameters tested are chlorine residual and Escherichia coli.

\section{B. Causal Loop Diagram}

This causal loop diagram showed the causal relationship of the interrelationship between variables which were inserted into the model structure.

Making the Stock-Flow Diagram:-

The stock-flow diagram on the PDAM distribution network model as shown in the Figure 2 was built based on the causal loop diagram.

Fig. 1:- Dynamic model of PDAM Distribution Network

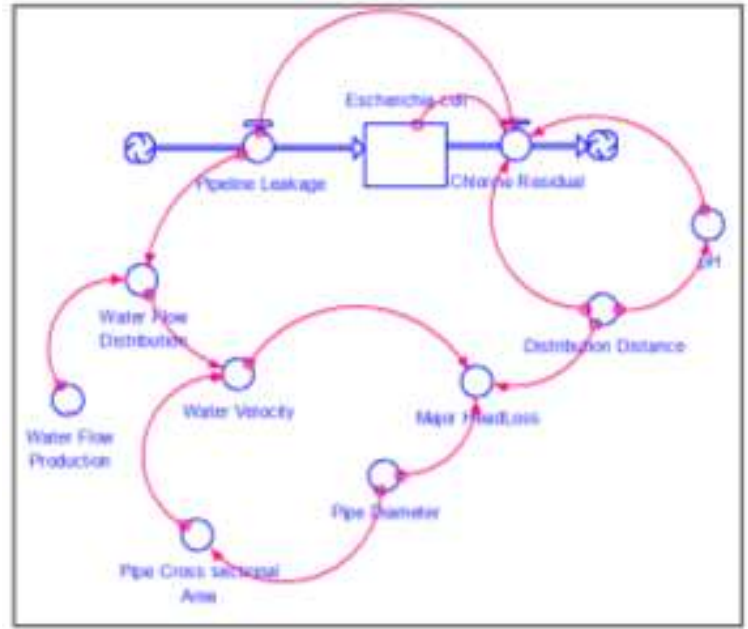




\section{Model Verification and Validation}

A. Model Verification

Based on the results of unit model verification and structure model verification, this model of PDAM network distribution has been going on well without any errors, both on the formulation and the unit.

\section{B. Model Validation}

\section{Model Structure Test}

The examination of model structure in this study has been done through literature study to understand the concept and the actual condition of PDAM network distribution

\section{Model Parameter Test}

This model used variables of chlorine residual and Escherichia coli which have negative loop relationship. That logic was compared with the simulation results which can be seen on the following Figure 2.

Fig. 2:- Parameter Test Model

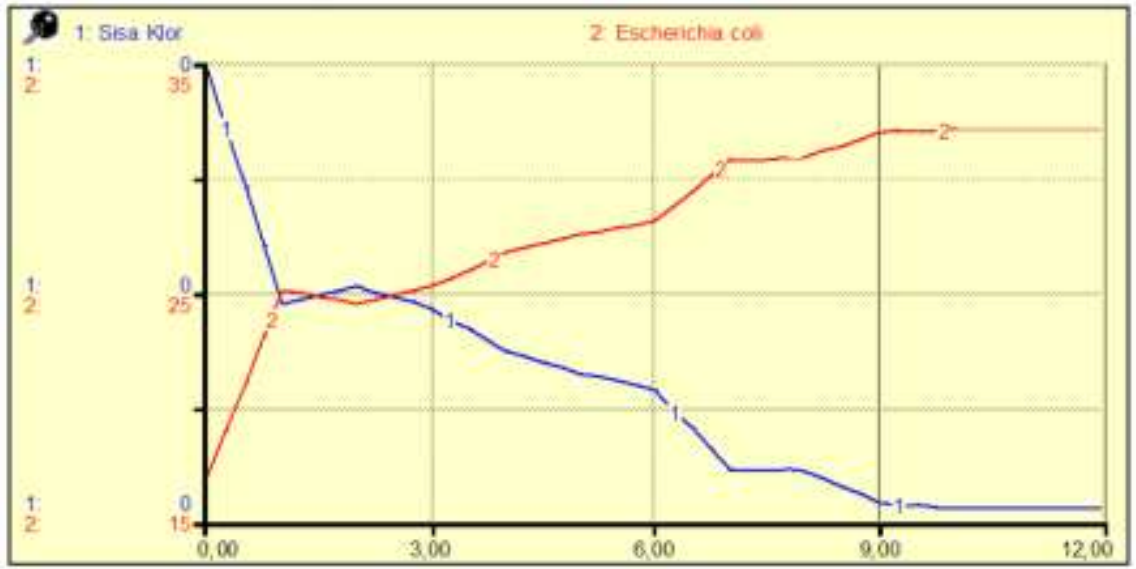

The result of the parameter test of the graph pattern above shows that the chlorine residual which was decreasing, increased the rate of Escherichia coli in the water. Based on the result, model simulation parameter has been going on in accordance with the actual logic. Thus, this model is valid.

Model Behavior Test/Replication

This method was done by comparing the value of simulation results with actual value to find out the error value from the model which has been built.

\section{Results:-}

\section{Model Simulations:-}

The model simulation of network distribution was done after the model had been stated as valid from the previous test. This model stimulation was based on two main scenarios which are extreme scenario and optimum scenario.

\section{A. Extreme Scenario}

This scenario was applied to look for the system when the percentage of pipe leakage is $70 \%$ which was following the asumption for highest pipeline leakage risk in PDAM. The simulation result showed on Figure 3 below. 
Fig. 3 Extreme Scenario Result

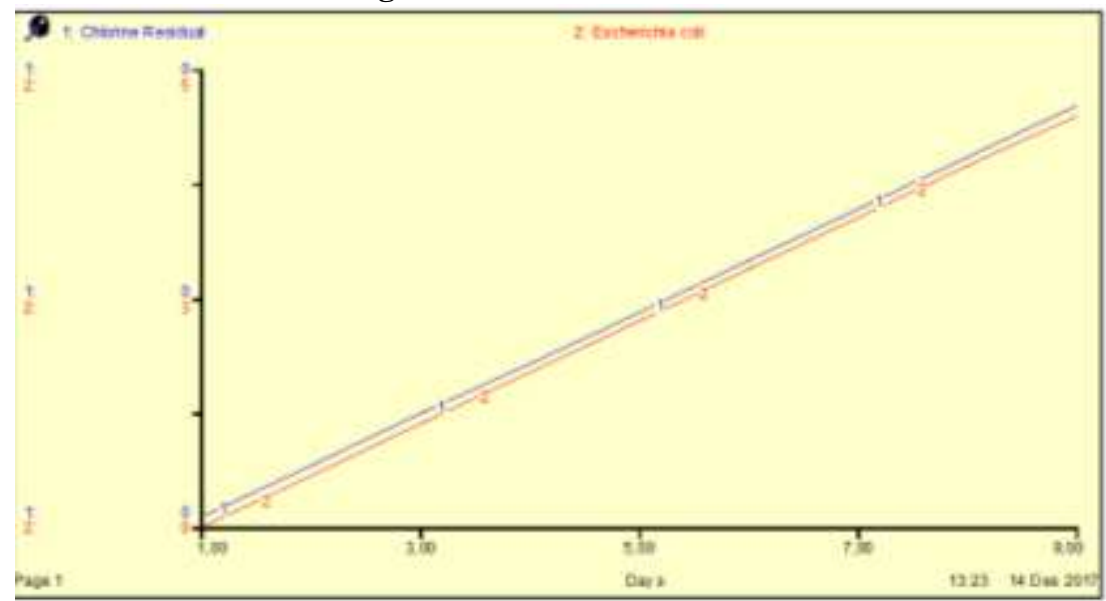

Figure 3 shows that Escherichia coli has increased 1 MPN / $100 \mathrm{ml}$ sample in every two days.

\section{B. Optimum Scenario}

This scenario was applied to look for the system when the percentage of pipe leakage is $10 \%$ which was following the asumption for the lowest pipeline leakage risk in PDAM. The simulation result is shown in the Figure 4 below..

Fig. 4:- Optimum Scenario Result

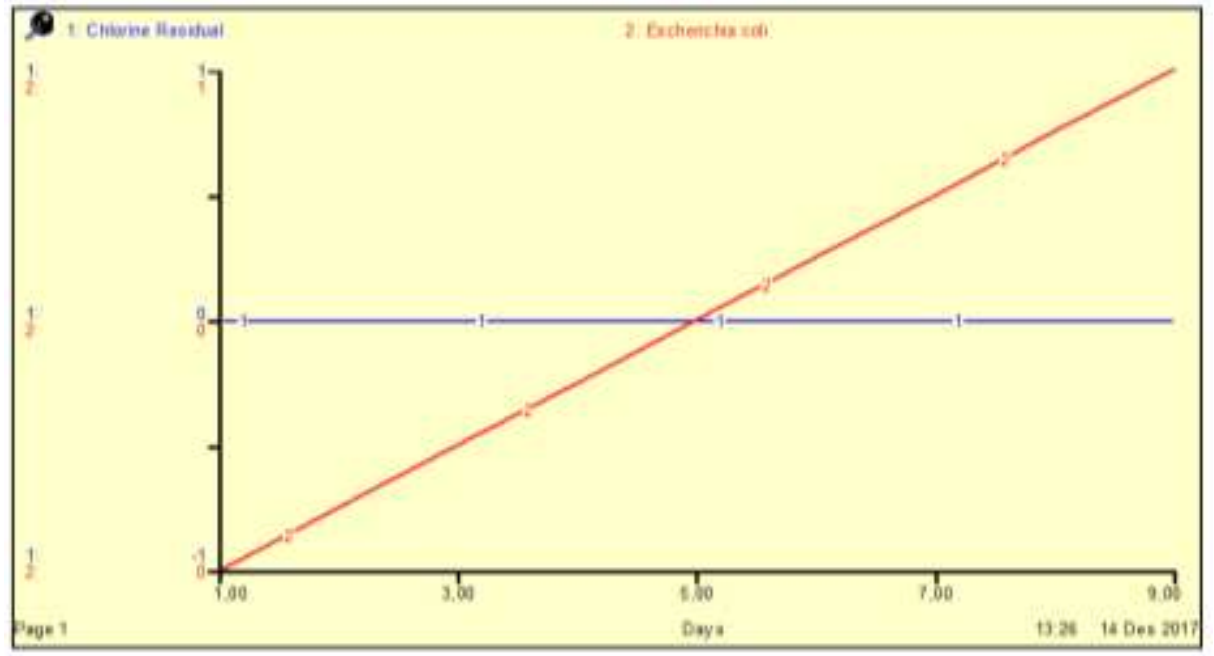

Figure 4 shows that 10\% pipeline leakage does not give any affect for Escherichia coli growth.

\section{Discussion:-}

In the extreme scenario, pipe leakage can cause organic matter into the distribution network so that bacterial growth becomes faster. According to Volk and LeChevallier, the growth of microorganisms is done by the amount of organic matter in the air. The more organic materials, the faster the bacteria growth caused by the content of organic matter becomes a source of carbon and energy for the growth and development of bacteria. Swiderska-Broz M (2003) stated that bacterial growth will not occur if the air does not contain inorganic and organic substrates so that the air can be said asbiologically stable.

Based on the simulation result at $5 \mathrm{~km}$ (the nearest consumer from water treatment plant), on the 6th to 9th day, Escherichia coli is predicted to be in distribution network about $1 \mathrm{MPN} / 100 \mathrm{ml}$ sample. This could occur due to the lowest pipeline leakage percentage and specially in this case study, there is no strong indication for the Escherichia coli presence in water such as sewage or animal waste contamination. However, the pipeline repairing and disinfectan injection should be done to reduce the public health risk even though the pipeline leakage percentage does not give any affect. 


\section{Conclusion:-}

After the data were analysed, the researcher concluded that the increasing of pipeline leakage percentage resulted in the disinfectant run out faster and the number of Escherichia coli increases every day, although the increase is not too significant. Moreover, in order to reduce public helth risk, it is necessary to repair pipes and to inject disinfectant when there are any pipeline leaks detected.

\section{Acknowledgements:-}

We would like to express our gratitude to PDAM Surabaya Indonesia who provided the data for this study. 